\title{
Caracterización fenotípica de aislamientos ambientales de Cryptococcus neoformans
}

\begin{abstract}
Sandra Huérfano ${ }^{1}$, Maria Caridad Cepero ${ }^{2}$, Elizabeth Castañeda ${ }^{1}$
${ }^{1}$ Grupo de Microbiología, Instituto Nacional de Salud, Bogotá, D.C., Colombia.

${ }^{2}$ Centro de Investigaciones Microbiológicas, Universidad de los Andes, Bogotá, D.C., Colombia.

La criptococosis es causada por las tres variedades de Cryptococcus neoformans, las cuales presentan diferencias fisiológicas y de virulencia, algunas de las cuales se han estudiado para reconocer aspectos de su biología. Este trabajo evaluó las características fenotípicas de aislamientos ambientales de las variedades grubii y gattii, con el fin de establecer diferencias asociadas con el ciclo de vida y la virulencia. Se estudiaron 28 aislamientos serotipo A y 31 serotipo C. Se evaluaron la morfología macroscópica y microscópica de blastoconidias cultivadas en agar Sabouraud y suelos, el crecimiento a $37^{\circ} \mathrm{C}$, la producción de 22 enzimas extracelulares, la frecuencia del fenómeno de fructificación haploide, la pareja sexual, el patrón de sensibilidad a toxinas asesinas (killer) y la virulencia en ratones Balb/c. No se observaron diferencias entre las dos variedades en la morfología macroscópica, la microscópica, ni en el crecimiento a $37^{\circ} \mathrm{C}(p>0,05)$; sin embargo, se observó disminución del tamaño celular y capsular de blastoconidias cultivadas en suelo comparado con el tamaño en Sabouraud $(p<0,05)$. Adicionalmente, se observó mayor actividad enzimática de proteasas, fosfolipasas, fenoloxidasa y $\beta$-glucosidasa en los aislamientos de la variedad grubii al compararlos con los aislamientos de la variedad gattii $(p<0,05)$. En las dos variedades se observaron estructuras relacionadas con fructificación haploide y todos los aislamientos fueron pareja sexual $\alpha$. Los patrones killer en los aislamientos de la var. grubii fueron el I y el II; en contraste, en la var. gattii se encontraron 7 patrones I, V, IX-XIII. En el modelo animal encontramos que 12 de 22 (54,5\%) aislamientos de la var. grubii causaron la muerte durante el periodo de observación, en tanto que ninguno de los 14 de la var. gattii la causó. La disminución del tamaño de las blastoconidias en suelo y la frecuencia de la pareja $\alpha$ con estructuras relacionadas con fructificación haploide sugieren un mecanismo importante para la producción de partículas infecciosas en la naturaleza. Adicionalmente, la mayor actividad enzimática de la var. grubii podría asociarse con su virulencia en el modelo animal.
\end{abstract}

Palabras clave: $C$. neoformans, var. grubii, var. gattii, factores de virulencia, aislamientos ambientales, ciclo de vida.

\section{Phenotypical characterization of Cryptococcus neoformans environmental isolates}

Cryptococcosis is caused by the three varieties of $C$. neoformans with physiological and virulence differences, some of which have been studied to determine biological aspects of this microorganism. The phenotypical aspects of environmental isolates from varieties grubii and gattii were evaluated to establish differences associated with their life cycle and virulence. To this end, 28 and 31 strains of $C$. neoformans serotypes $A$ (var. grubii) and $C$ (var. gattii) were studied. The microscopic and macroscopic morphology on Sabouraud agar and soils, growth rate at $37^{\circ} \mathrm{C}$, production of 22 extracellular enzymes, haploid fructification, mating type, killer toxin sensitivity patterns and virulence in BALB/c mice were evaluated. No differences were observed between the two varieties regarding microscopic and macroscopic morphology or growth at $37^{\circ} \mathrm{C}(p>0.05)$. However, a decrease in the cellular and capsular sizes of yeast in soil, as compared to Sabouraud, was observed $(p<0.05)$. Aditionally, higher enzimatic activity of proteases, phospholipases, phenoloxidase and $\beta$-glucosidase was observed in var. grubii isolates as compared to var. gattii $(p<0.05)$. In both varieties, structures related with haploid fruitification were observed and all isolates were mating type $\alpha$. Killer toxin sensitivity patterns 
of the isolates of var. grubii were I and II; in contrast, in var. gattii, seven different patterns were found: I, V, IX-XIII. In the animal model we found that 12 of $22(54.5 \%)$ isolates of var. grubii caused the death of the mice during the observation period, while none of the 14 var. gattii isolates caused it. The decrease in capsular and cellular sizes of the yeast in soil and the frequency of mating type $\alpha$ with structures related to haploid fructification suggest an important mechanism of production of infectious particles in nature. Additionally, greater enzimatic activity of var. grubii can be associated with the virulence in the animal model.

Key words: C. neoformans, var. grubii, var. gattii, virulence factors, environmental isolates, life cycle.

Cryptococcus neoformans es una levadura patógena de la cual se reconocen 3 variedades: C. neoformans var. grubii, serotipo A, C. neoformans var. neoformans, serotipo $D$ y $C$ y neoformans var. gattii, serotipos B y C; estas variedades tienen marcadas diferencias bioquímicas, serológicas, epidemiológicas, geográficas y de virulencia $(1,2)$.

En cuanto a los factores de virulencia de $C$. neoformans, los estudios realizados con aislamientos mutantes han permitido establecer algunos que probablemente contribuyen a la patogénesis, tales como la producción de la cápsula, la presencia de las enzimas fenoloxidasa y fosfolipasa y el crecimiento a $37{ }^{\circ} \mathrm{C}$. Adicionalmente, existen evidencias sobre otras características como la pareja sexual $\alpha$ y la producción de proteasas y otras enzimas extracelulares que podrían estar asociadas con la virulencia (2-4). No obstante, se desconoce cómo se regulan estas características fenotípicas y de qué manera su expresión regula el fenotipo virulento.

Por otra parte, es importante anotar que el estudio de la ecología de este hongo se ha dificultado debido a que no se conocen con exactitud su hábitat primario ni su ciclo reproductivo en el ambiente, por lo cual también se desconocen algunos aspectos de la fisiopatología de la enfermedad que ocasiona, como son la naturaleza de la partícula infecciosa y el momento de adquisición de la infección con respecto al desarrollo de la sintomatología (2-4).

Correspondencia:

Sandra Huérfano. Grupo de Microbiología, Laboratorio B203, Instituto Nacional de Salud, Avenida calle 26 No.51-60, Bogotá, D.C., Colombia; teléfono: 220 7700, extensión 446 sandrahm10@yahoo.com

Recibido: 12/05/03; aceptado: 14/08/03
En este trabajo nos propusimos determinar algunos aspectos fenotípicos en aislamientos ambientales colombianos de $C$. neoformans var. grubii serotipo A y var. gattii serotipo C, con el fin de comprender aspectos de la fisiología del hongo que servirán como base para responder a interrogantes acerca de su patogenicidad y ciclo de vida.

\section{Materiales y métodos}

\section{Aislamientos de C. neoformans}

Se estudiaron 28 aislamientos de la variedad grubii, serotipo A, recuperados de material relacionado con árboles (detritos, $n=16$, pulpa de semillas, $n=9$, cáscaras de semillas, $n=2$ y polvo de viviendas, $n=1$ ) en trabajos previamente realizados en Cúcuta y Bogotá entre 1996 y 1999. Se estudiaron también 31 aislamientos de la variedad gattii, serotipo $\mathrm{C}$, recuperados de detritos de almendros en estudios realizados en Cúcuta entre 1997 y 1999.

Los aislamientos de $C$. neoformans se recuperaron del cepario del Grupo de Microbiología a partir de tubos con agar glucosado de Sabouraud preservados a $4{ }^{\circ} \mathrm{C}$ y otros a partir de viales con una suspensión de la levadura en agua destilada estéril, preservados a temperatura ambiente (5). Para la confirmación de los aislamientos se siguió un protocolo que incluyó la observación de la cápsula, la evaluación de la actividad de la ureasa, la evaluación del crecimiento en agar CGB y la aglutinación con antisueros específicos (Cryptocheck, latron®-Japón) (6).

De estos aislamientos se conocían los patrones moleculares establecidos por la técnica de PCRhuella digital. Todos los aislamientos de la variedad grubii pertenecían al patrón molecular VN I, 30 de los de la variedad gattiise agruparon en el patrón 
VG III y un aislamiento fue designado con el patrón VG IV (comunicación personal; A. Castañeda, W. Meyer).

\section{Crecimiento a $37^{\circ} \mathrm{C}$}

Se sembraron los aislamientos en tubos de agar glucosado de Sabouraud y se incubaron a $37^{\circ} \mathrm{C}$ por 72 horas; la lectura se realizó evaluando el crecimiento de la levadura sobre el agar.

\section{Morfología macroscópica}

La morfología macroscópica se evaluó con base en la textura y el aspecto de colonias aisladas al ser cultivadas en agar glucosado de Sabouraud durante 7 días a $30^{\circ} \mathrm{C}(7)$.

\section{Tamaño celular y capsular de blastoconidias cultivadas en caldo de Sabouraud y en suelo}

Se empleó un cultivo de 48 horas en caldo glucosado de Sabouraud incubado a $30^{\circ} \mathrm{C}$ en agitación (150 rpm) y se realizó una preparación con tinta china que se observó al microscopio con aumento de 1000X; la medición del diámetro se realizó con un micrómetro $(7,8)$. Para el cultivo en suelo se sembraron los aislamientos en agar glucosado de Sabouraud y se incubaron durante 48 horas a una temperatura de $27^{\circ} \mathrm{C}$; posteriormente se realizaron suspensiones ajustadas al patrón 10 de McFarland y se inocularon $30 \mathrm{~g}$ de suelo con $7,5 \mathrm{ml}$ de cada suspensión. Los suelos se mantuvieron a temperatura ambiente y se humedecieron semanalmente. La observación para determinar los tamaños celular y capsular se realizó a los 30 días.

\section{Proteasas y fosfolipasas}

Se evaluó la producción de proteasas en agar base carbono de levadura (YCB) suplementado con albúmina sérica bovina y polipeptona (9) y la producción de fosfolipasas en agar glucosado de Sabouraud suplementado con yema de huevo (10). La lectura se realizó determinando los índices $\mathrm{Pz}$ (diámetro de la colonia dividido por el diámetro de la colonia más la zona de precipitado o hidrólisis $(9,11,12)$. Se determinaron rangos de actividad enzimática de acuerdo con los valores $\mathrm{Pz}$ así: $\mathrm{Pz}=1$, actividad negativa; $\mathrm{Pz}=0,7-0,99$, actividad baja; $P z=0,5-0,69$, actividad media, y $P z<0,5$, actividad alta (3).

\section{Semicuantificación de la fenoloxidasa}

Se evaluó en un medio mínimo suplementado con L-Dopa. La lectura se realizó de acuerdo con la intensidad del pigmento producido (7) y se clasificó como $0=$ actividad negativa; $0,5-1$, actividad baja; 2, actividad media, y 3-4, actividad alta (3). La semicuantificación de la enzima se realizó por triplicado para cada aislamiento; para la presentación de los resultados se calculó el promedio de los 3 ensayos.

\section{Evaluación de la actividad de 19 enzimas extracelulares}

La actividad enzimática de otras enzimas extracelulares se evaluó con el método del Api Zim para 20 aislamientos de la variedad grubii y 20 aislamientos de la variedad gattii. El procedimiento, lectura e interpretación se llevó a cabo de acuerdo con las indicaciones de la casa comercial (bioMérieux). Se determinaron rangos de actividad enzimática de acuerdo con la intensidad: $0=$ negativa; $1-2$, baja; $3-4$, media, y 5 , alta (3).

\section{Fructificación haploide}

Se evaluó el fenómeno en agar filamentoso (13) incubado a $27^{\circ} \mathrm{C}$ durante 60 días. Se realizaron preparaciones en fresco y se observaron en microscopio de luz, con aumentos de 400X y 1000X. Se interpretó como positivo para el fenómeno la formación de estructuras relacionadas con fructificación haploide (tubos germinales, hifas o basidios) y negativo cuando se observaron solamente blastoconidas (13).

\section{Evaluación del fenómeno de toxinas asesinas}

La inhibición del crecimiento de $C$. neoformans producida como resultado de la interacción con las toxinas producidas por 6 levaduras relacionadas con el filo Basidiomycota, se evaluó en cajas de agar extracto de levadura-peptonaglucosa (YEPD) con azul de metileno. La interpretación se realizó de acuerdo con los patrones establecidos (14).

\section{Animales}

Se emplearon ratones BALB/c machos de 3 a 5 semanas, obtenidos del bioterio del INS. Durante 
el estudio se mantuvieron en la sala de alta seguridad del bioterio, con una humedad relativa de entre $40 \%$ y $60 \%$ y una temperatura entre 18 y $22{ }^{\circ} \mathrm{C}$; los animales se alimentaron diariamente con agua y Rodentina ${ }^{\circledR}$ (Purina). El manejo de animales se realizó de acuerdo con las recomendaciones nacionales (Ley 84 de 1989, resolución 8430 de 1993), internacionales (Consejo de Comunidades Europeas y del Concilio Canadiense sobre el cuidado de animales de 1998) y el protocolo de uso de animales del INS.

\section{Pruebas de virulencia en ratones}

Los ratones se inocularon en la vena marginal de la cola con $0,1 \mathrm{ml}$ de una suspensión de blastoconidias. La virulencia se evaluó con base en la supervivencia de los ratones; adicionalmente, se documentó la diseminación del hongo a los órganos con el recuento de unidades formadores de colonia (UFC) por gramo de órgano (bazo, pulmón y cerebro), al igual que con la observación al microscopio de los macerados de los tejidos en preparación con tinta china.

Se realizaron dos ensayos, el primero con el fin de determinar la virulencia de aislamientos de las dos variedades del hongo con la inoculación de una dosis estándar de $5 \times 10^{5}$ UFC en grupos de 3 ratones por aislamiento; se emplearon 22 aislamientos de la variedad grubii y 14 aislamientos de la variedad gattii. En el segundo ensayo se realizó una curva de dosis con el fin de evaluar la relación entre concentración del inóculo y la virulencia. Para este ensayo se seleccionó 1 aislamiento de cada variedad con base en los resultados del primer ensayo. Los aislamientos empleados fueron el NS-579 (código 40) serotipo A y el aislamiento INS-560 (código 1) serotipo C; los inóculos fueron ajustados a 2,5, 5 y $10 \times 10^{5}$ UFC. Se inocularon grupos de 5 ratones con cada una de las concentraciones establecidas.

Los ratones fueron observados diariamente durante un período de 70 días; durante este período, los ratones que murieron se procesaron al igual que los que se encontraban adinámicos o erizados, previa eutanasia con $\mathrm{CO}_{2}$; los restantes se sacrificaron el día 70 post-inoculación con el empleo del mismo procedimiento.

\section{Determinación de la pareja sexual a o $\alpha$ por la} reacción en cadena de la polimerasa (PCR)

Para la PCR se realizó la extracción del ADN empleando congelamiento con nitrógeno líquido y fricción como métodos físicos para romper la pared; adicionalmente, se usó una solución tampón de extracción con ácido triiso-propilnaftaleno sulfónico y ácido 4-aminosalisílico (15). Se emplearon los iniciadores MF $\alpha$ U 5'TTC ACT GCC ATC TTC ACC ACC 3' y MF $\alpha$ L 5'TCT AGG CGA TGA CAC AAA GGG 3' que codifican para una feromona específica de la pareja $\alpha$ de $C$. neoformans. Adicionalmente, para evitar falsos negativos, cuando no se presentó amplificación con los iniciadores MF $\alpha$, se realizó una coam-plificación con los iniciadores ITS $15^{\prime}$ TCC GTA GGT GAA CCT GCG G 3' e ITS 4 5' TCC TCC GCT TAT TGA TAT GC 3', los cuales son específicos para hongos. La visualización de los productos de PCR se realizó por electroforesis en gel de agarosa al $2 \%$ y se tomó fotografía para evaluar la presencia de una banda de 109 pb correspondiente al producto amplificado con los iniciadores MF $\alpha$ y una banda de 500 pb correspondiente al producto amplificado con los iniciadores ITS (16).

\section{Cepas control}

Las cepas control empleadas en este estudio fueron Pseudomonas aeruginosa ATCC 27853 para la estandarización de la técnica de perfil enzimático por el micrométodo Api zim; $C$. neoformans CBS 886, 6886,889 y 1584 para los patrones de toxinas asesinas, Cryptococcus laurentii CBS 139, 7235 y 7857, Cryptococcus humicola CBS 4281, Cryptococcus podzolicus CBS 7717 y Filobasidium capsuligenum CBS 4736 como aislamientos productores de toxinas (suministradas por T. Boekhout del CBS, Holanda) y C. neoformans JEC 20 (a) y $21(\alpha)$ para la fructificación haploide y la PCR para pareja sexual (suministradas por J. Heitman, Universidad de Duke, E.E.U.U).

\section{Análisis estadístico}

Las comparaciones de los porcentajes de rangos de actividad enzimática, de aislamientos virulentos por variedad, de media aritmética de los índices $\mathrm{Pz}$ y del tamaño capsular y celular de 
blastoconidias se realizaron en el programa estadístico Epi-info 6.0 mediante la prueba de Fischer con un nivel de significancia de $p<0,05$.

\section{Resultados}

\section{Confirmación de los aislamientos}

Todos los aislamientos fueron capsulados y presentaron actividad de la ureasa; los aislamientos de la variedad grubii no crecieron en el agar CGB y aglutinaron con el antisuero antiserotipo $A$; en contraste, los aislamientos de la variedad gattii crecieron en agar CGB causando el viraje de color de este medio y se observó aglutinación con el antisuero anti-serotipo C.

\section{Crecimiento a $37^{\circ} \mathrm{C}$}

Todos los aislamientos pertenecientes a las dos variedades crecieron adecuadamente a $37^{\circ} \mathrm{C}$.

\section{Morfología macroscópica}

La textura y el aspecto de la gran mayoría de las colonias de los aislamientos de $C$. neoformans var. grubii fueron similares, no mucosas, de superficie y borde liso. Sin embargo, se observaron variantes morfológicas en algunas colonias de 4 aislamientos, las cuales presentaron textura mucosa $\mathrm{o}$ aspecto de borde ondulado o irregular. En contraste, todas las colonias de los aislamientos de $C$. neoformans var. gattii fueron macroscópicamente similares, no mucosas y de borde liso.

\section{Tamaño celular y capsular de blastoconidias sembradas en caldo Sabouraud y suelo}

Cuando se cultivaron en caldo glucosado de Sabouraud, las dos variedades del hongo presentaron similar tamaño celular, con un promedio de $5 \pm 0,6 \mu \mathrm{m}$ y $4,82 \pm 0,58 \mu \mathrm{m}$ para las variedades grubii y gattii, respectivamente; en suelo, el tamaño celular fue significativamente menor para las dos variedades con un promedio de $4,34 \pm 0,48 \mu \mathrm{m}$ y $4,23 \pm 0,42 \mu \mathrm{m}$ para las variedades grubii y gattii, respectivamente.

Cuando las blastoconidias se cultivaron en caldo glucosado de Sabouraud, el tamaño capsular para las dos variedades del hongo fue también similar, con un promedio de $0,87 \pm 0,39 \mu \mathrm{m}$ y $1,04 \pm 0,53$ $\mu \mathrm{m}$ para las variedades grubii y gattii, respectivamente. Sin embargo, en el suelo, el tamaño fue significativamente menor y adicionalmente se observaron diferencias estadísticamente significativas en el tamaño capsular de las dos variedades $(p=0,009)$ con un promedio de $0,11 \pm 0,05 \mu \mathrm{m}$ y $0,34 \pm 0,16 \mu \mathrm{m}$ para las variedades grubiiy gattii, respectivamente.

\section{Proteasas y fosfolipasas}

En la actividad de proteasas no se observó diferencia significativa para las dos variedades de C. neoformans cuando se analizó la media del valor $\mathrm{Pz}(0,63 \pm 0,06$ y $0,72 \pm 0,06$ variedad grubii y gattii, respectivamente). Sin embargo, al evaluar los grupos por rangos de actividad enzimática para las dos variedades, se encontraron diferencias estadísticamente significativas en las actividades media y baja. Es importante destacar que siempre se observó una mayor actividad enzimática para los aislamientos de la variedad grubii (cuadro1).

La actividad de la fosfolipasa fue evaluada los días 6 y 10 de incubación y se observó una marcada diferencia en la lectura en los dos períodos. El día 6 , los 28 aislamientos de C. neoformans var. grubii presentaron algún grado de actividad de la enzima; en contraste, sólo 13 de 31 (42\%) de los aislamientos de la var. gattii mostraron actividad. Sin embargo, en la lectura realizada el día 10 se observó que 29 de 31 (93,5\%) aislamientos de la var. gattii mostraban baja actividad (dato no presentado). En cuanto a la actividad de esta enzima para el día 6 , se observaron diferencias significativas $(p<0,001)$ cuando se analizó la media del valor $\mathrm{Pz}, 0,7 \pm 0,11$ y $0,91 \pm 0,1$ para las variedades grubii y gattii, respectivamente. Adicionalmente, al evaluar los grupos por rangos de actividad enzimática para las dos variedades, se encontraron diferencias estadísticamente significativas en los rangos de actividad media y no actividad. La mayor actividad se observó en los aislamientos de la variedad grubii (cuadro 1).

\section{Fenoloxidasa}

Todos los aislamientos de las dos variedades del hongo presentaron actividad de la enzima en medio mínimo con L-Dopa. Se observaron diferencias estadísticamente significativas $(p<0,001)$ en el promedio de los datos de las dos variedades con un valor de $3,73 \pm 0,9$ y $2,62 \pm 1,3$ para las variedades 
Cuadro 1. Rango de actividad de proteasas y fosfolipasas en los aislamientos de $C$. neoformans de las variedades grubi y gattii.

\begin{tabular}{|c|c|c|c|}
\hline \multirow{2}{*}{$\begin{array}{l}\text { Enzimas y rango } \\
\text { de actividad }\end{array}$} & \multicolumn{2}{|c|}{ Variedad } & \multirow[t]{2}{*}{$p$} \\
\hline & $\begin{array}{c}\text { grubii }(\mathrm{n}=28) \\
\mathrm{n}^{\star}(\%)\end{array}$ & $\begin{array}{c}\text { gattii }(\mathrm{n}=31) \\
\mathrm{n}^{*}(\%)\end{array}$ & \\
\hline \multicolumn{4}{|l|}{ 1. Proteasas } \\
\hline Alta & $1(3,6)$ & $0(0)$ & $>0,5$ \\
\hline Media & $19(67,8)$ & $12(38,7)$ & 0,025 \\
\hline $\begin{array}{l}\text { Baja } \\
\text { 2. Fosfolipasas }\end{array}$ & $8(28,6)$ & $19(61,3)$ & 0,011 \\
\hline Alta & $1(3,6)$ & $0(0)$ & $>0,5$ \\
\hline Media & $13(46,4)$ & $0(0)$ & $\leq 0,001$ \\
\hline Baja & $14(50)$ & $13(42)$ & 0,5 \\
\hline No actividad & $0(0)$ & $18(58)$ & $\leq 0,001$ \\
\hline
\end{tabular}

* $\mathrm{n}=$ número de aislamientos con actividad

grubii y gattii, respectivamente. Adicionalmente, al evaluar los grupos por rangos de actividad enzimática para las dos variedades, se observaron diferencias significativas en el rango de actividad alta; en contraste, no se observaron diferencias entre variedades en los rangos de actividad media y baja. La mayor actividad enzimática fue detectada en los aislamientos de la variedad grubii (cuadro 2).

\section{Evaluación de la actividad de 19 enzimas extracelulares}

Se observó que todos los aislamientos presentaron actividad de la esterasa $\mathrm{C} 4$, leucina arilamidasa, fosfatasa ácida y naftol fosfohidrolasa; 39 de 40 de los aislamientos evaluados presentaron actividad de la enzima esterasa lipasa C-8. Se observó actividad enzimática variable en las dos variedades de $C$. neoformans evaluadas con la valina arilamidasa, $\alpha$-galactosidasa, $\beta$ glucoronidasa, $\alpha$-glucosidasa, $\beta$-glucosidasa, $N$ acetil- $\beta$-glucosamida. Adicionalmente, la actividad de la fosfatasa alcalina sólo se observó en aislamientos de la variedad gattii. No se observó actividad en ninguno de los 40 aislamientos estudiados para las enzimas lipasa C-14, cisteina arilamidasa, tripsina, quimiotripsina, $\beta$ galactosidasa, $\alpha$-manosidasa ni $\alpha$-fucosidasa. Al realizar el análisis estadístico de los resultados de la intensidad de la actividad enzimática en las dos variedades de $C$. neoformans se observaron diferencias significativas para la fosfatasa alcalina en los rangos de actividad baja $(p<0,0001)$ y
Cuadro 2. Rango de actividad de la fenoloxidasa en los aislamientos de $C$. neoformans de las variedades grubii y gattii.

\begin{tabular}{lccc}
\hline Promedio de & \multicolumn{2}{c}{ Variedad } & $p$ \\
\cline { 2 - 4 } actividad enzimática & $\begin{array}{c}\text { grubii } \\
(\mathbf{n = 2 8}) \\
\mathbf{n}^{*}(\%)\end{array}$ & $\begin{array}{l}\text { gattii } \\
(\mathbf{n}=\mathbf{3 1})\end{array}$ & \\
$\mathbf{n}^{\star}(\%)$ & \\
\hline Alta & $26(92,9)$ & $21(67,75)$ & 0,0167 \\
Media & $0(0)$ & $2(6,45)$ & $>0,5$ \\
Baja & $2(7,1)$ & $8(25,8)$ & 0,118 \\
\hline
\end{tabular}

${ }^{*} \mathrm{n}=$ aislamientos con actividad

ausencia de actividad $(p<0,001)$ y para la $\alpha$ glucosidasa en los rangos de actividad baja $(p=0,025)$, media $(p=0,012)$ y ausencia de actividad $(p=0,038)$. La mayor actividad se observó en los aislamientos de la variedad gattii. En contraste, la enzima $\beta$-glucosidasa mostró mayor actividad en los aislamientos de la variedad grubii cuando se analizaron los rangos de actividad baja $(p=0,038)$ y ausencia de actividad $(p=0,038)$.

\section{Fructificación haploide}

Se realizaron 3 ensayos con todos los aislamientos. Para todos los ensayos se sembraron los controles por triplicado; sin embargo, el control positivo (JEC 21) no presentó estructuras de fructificación haploide en las tres replicas. Se observó que los aislamientos estudiados no se comportaban igual en los 3 ensayos, señalando así la baja reproducibilidad de la prueba. Por esta razón, para el análisis de datos se tuvo en cuenta la formación de estructuras relacionadas con fructificación haploide en, por lo menos, uno de los tres ensayos. Se encontró que para la variedad grubii ningún aislamiento presentaba producción de hifas ni basidios; sin embargo, se observaron tubos germinales en dos aislamientos. En contraste, en un aislamiento de la variedad gattii se desarrollaron hifas y basidios y en 30 aislamientos se observaron tubos germinales.

\section{Fenómeno de toxinas asesinas}

Los patrones para la variedad grubii fueron I (27/ 28) y II (1/28); en contraste, se observaron 7 patrones para los aislamientos de la variedad gattii, I (1/31), V (6/31), IX (1/31), X (4/31) y 3 patrones que no habían sido informados anteriormente, los 
cuales se designaron como XI (10/31) XII (8/31) y XIII (1/31).

\section{Virulencia en ratones}

En el primer ensayo, de los 22 aislamientos de la variedad grubii empleados se observó que sólo 12, denominados letales, causaron la muerte de los ratones. En contraste, ninguno de los 14 aislamientos de la variedad gattii causó la muerte de los animales $(p=0,0025)$. En la figura 1 se pueden observar las curvas de supervivencia de los grupos de animales inoculados con estos aislamientos letales de la variedad grubii, en los que se destaca la virulencia del aislamiento 40 (INS 579), el cual causó la muerte de los animales 15 días post-inoculación.

Se recuperó el hongo a partir de cerebro en los 22 grupos de ratones inoculados con los aislamientos de la variedad grubii; en contraste, sólo se recuperó el hongo a partir de 10 de los 14 grupos de ratones inoculados con aislamientos de la variedad gattii; la diseminación en los demás órganos fue variable. Es importante resaltar que la diseminación simultánea en los 3 órganos (cerebro, pulmón y bazo) fue más frecuente en los grupos de ratones inoculados con los aislamientos denominados letales (8/12) que en los no letales de la variedad grubii (4/10) y gattii $(0 / 14)$. En general, se recuperó mayor número de UFC a partir de cerebro que de bazo o pulmón para las dos variedades del hongo (cuadro 3 ).

Al realizar la observación microscópica de los macerados de los órganos con tinta china, se observó una correlación de 100\% con el cultivo; adicionalmente, se encontraron levaduras con tamaño capsular entre 5 y $11 \mu \mathrm{m}$ en los órganos de los ratones inoculados con los aislamientos letales, en tanto que el tamaño de la cápsula fue entre 0 y $2 \mu \mathrm{m}$ de las levaduras presentes en los órganos de los ratones inoculados con los aislamientos no letales de las dos variedades de C. neoformans (datos no presentados).

En el segundo ensayo, las 3 diferentes dosis del aislamiento 40 (INS 579) de la variedad grubii causaron en los animales alguna sintomatología (ratones erizados y adinámicos), la cual se observó entre los días 15 y 20 post-inoculación, por lo cual en el día 20 se les practicó la eutanasia con $\mathrm{CO}_{2}$. El hongo fue recuperado de bazo, pulmón y cerebro de los grupos de animales inoculados con las diferentes dosis. En general, se observó mayor recuento de UFC/g en cerebro y pulmón para los ratones con dosis más altas, mientras

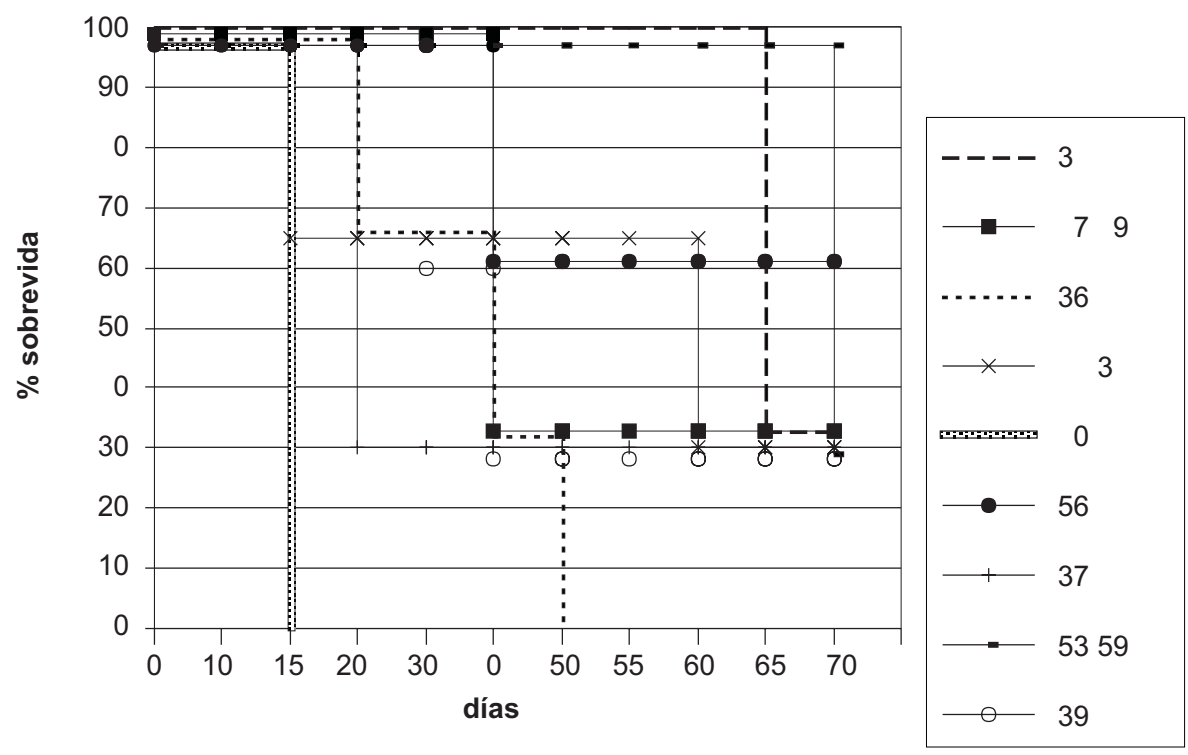

Figura 1. Curvas de supervivencia de los 12 grupos de ratones inoculados con aislamientos letales de $C$. neoformans var. grubii con dosis de $5 \times 10^{5}$ UFC. 
Cuadro 3. Rangos de UFC recuperadas a partir de los órganos de los animales inoculados con las dos variedades de C. neoformans.

\begin{tabular}{lccr}
\hline Órgano & \multicolumn{3}{c}{ Rangos UFC $/ \mathbf{g}^{*}$} \\
\cline { 2 - 4 } & Letales & var. grubii & vo letales \\
\hline Cerebro & $210-7,1 \times 10^{7}$ & $250-3 \times 10^{9}$ & $57-2,8 \times 10^{8}$ \\
Bazo & $660-1,7 \times 10^{6}$ & $660-7,6 \times 10^{4}$ & $630-5 \times 10^{3}$ \\
Pulmón & $120-2,2 \times 10^{6}$ & $330-9,3 \times 10^{7}$ & $3,9 \times 10^{3}-3,3 \times 10^{6}$ \\
\hline
\end{tabular}

${ }^{*} \mathrm{UFC} / \mathrm{g}=$ unidades formadoras de colonia por gramo de órgano

que el comportamiento en bazo fue irregular (cuadro 4).

Al realizar el examen macroscópico de los órganos, se observó que en el cerebro de los ratones inoculados con 5 y $10 \times 10^{5}$ UFC se presentaba infiltración de líquidos; en contraste, el cerebro en los ratones inoculados con 2,5 $\times 10^{5}$ UFC tenía apariencia normal, al igual que el pulmón y el bazo de todos los animales inoculados con las diferentes dosis. En el examen directo con tinta china del macerado de los órganos de los 15 ratones inoculados con las 3 dosis, se observaron levaduras con un tamaño capsular entre 5 y $11 \mu \mathrm{m}$.

Los ratones inoculados con las 3 diferentes dosis del aislamiento 1 (INS 560) de la variedad gattii no mostraron ninguna sintomatología, por lo cual se sacrificaron en el día 70 post-inoculación. En general, se logró recuperar el hongo en el cerebro, el bazo y el pulmón de los ratones inoculados con las dosis de 2,5 y $5 \times 10^{5}$ y solamente en el cerebro de los inoculados con dosis de $10 \times 10^{5}$ UFC. El recuento de UFC fue mayor en cerebro para los ratones inoculados con la dosis más alta; en contraste, se observó un comportamiento irregular en las UFC de bazo y pulmón (cuadro 4). Los órganos de los animales inoculados con la variedad gattii fueron normales al examen macroscópico y el tamaño de la cápsula de las levaduras en el macerado de órganos osciló entre 0 y $2 \mu \mathrm{m}$.

\section{PCR con iniciadores MF $\alpha$}

Todos los aislamientos de C. neoformans var. grubii y var. gattii amplificaron con los iniciadores MF $\alpha$, lo cual se visualizó en la electroforesis como un producto de $109 \mathrm{pb}$. Esto indica que todos los aislamientos tenían el gen que codifica para la feromona de la pareja sexual $\alpha$ (figura 2).

\section{Discusión}

Actualmente, y a pesar de los diversos estudios realizados sobre las variedades de $C$. neoformans, aún se desconocen aspectos de su metabolismo, virulencia y ecología $(3,4,17,18)$. Por esta razón, nuestro estudio evaluó diversos aspectos fenotípicos de aislamientos ambientales de dos variedades: var. grubii serotipo A y var. gattii serotipo C. Estos dos serotipos son los recuperados con mayor frecuencia en Colombia

Cuadro 4. Unidades formadoras de colonia (UFC) recuperadas a partir de los órganos de los animales inoculados con diferentes dosis de los aislamientos de $C$. neoformans variedad grubii INS-579 y de $C$. neoformans variedad gattii INS-560.

\begin{tabular}{lcccc}
\hline $\begin{array}{l}\text { Aislamiento inoculado } \\
\text { INS }\end{array}$ & $\begin{array}{c}\text { Concentración del inóculo } \\
\text { UFC X10 }\end{array}$ & Bazo & $\begin{array}{c}\text { UFC/ g recuperadas por órgano* } \\
\text { Pulmón }\end{array}$ & $\begin{array}{c}\text { Cerebro } \\
\text { var. grubii }\end{array}$ \\
& 2,5 & $3,2 \times 10^{4}$ & $2,6 \times 10^{6}$ & $0,28 \times 10^{8}$ \\
& 5 & $4,1 \times 10^{6}$ & $3,2 \times 10^{6}$ & $0,98 \times 10^{8}$ \\
var. gattii & 10 & $0,35 \times 10^{6}$ & $3,25 \times 10^{6}$ & $6,7 \times 10^{8}$ \\
& 2,5 & & & \\
& 5 & $4,6 \times 10^{2}$ & $0,27 \times 10^{2}$ & $0,15 \times 10^{2}$ \\
& 10 & $0,2 \times 10^{2}$ & $0,73 \times 10^{2}$ & $6,6 \times 10^{2}$ \\
& & 0 & 0 & $1,2 \times 10^{5}$ \\
\hline
\end{tabular}

\footnotetext{
${ }^{*}=$ Representa un promedio de las UFC obtenidas en cada uno de los 5 ratones empleados.
} 
en muestras procedentes de material vegetal (19). El objetivo fue determinar características asociadas con la patogenicidad del hongo y el ciclo de vida en la naturaleza y establecer patrones de sensibilidad a toxinas asesinas.

\section{Características asociadas con virulencia}

Crecimiento a $37^{\circ} \mathrm{C}$ y morfología macroscópica y microscópica. Para C. neoformans se ha descrito que el crecimiento a $37^{\circ} \mathrm{C}$, junto con la habilidad de crecer en atmósfera de $5 \%$ de $\mathrm{CO}_{2}$ y pH de 7,3 a 7,4 son características básicas de patogenicidad, determinadas por la presencia del gen de la calcineurina $A$, el cual codifica para una enzima involucrada en la respuesta al estrés fisiológico (20). Los resultados obtenidos en este ensayo permitieron inferir que todos los aislamientos estudiados cumplen estas características básicas de patogenicidad, lo cual los clasificó como adecuados para realizar la evaluación de virulencia en el modelo animal.

Recientemente, se ha descrito que colonias de C. neoformans con morfología macroscópica mucosa o rugosa son más virulentas que colonias que muestran pseudohifas o morfología lisa (21). En este estudio observamos que los aislamientos de las dos variedades del hongo presentaban colonias con una morfología que podría asociarse con "baja virulencia". Sin embargo, se observó el fenómeno de variación morfológica o swithching fenótipico en 4 aislamientos de la var. grubii. Este fenómeno ha sido postulado como un importante mecanismo para incrementar la virulencia (22). No

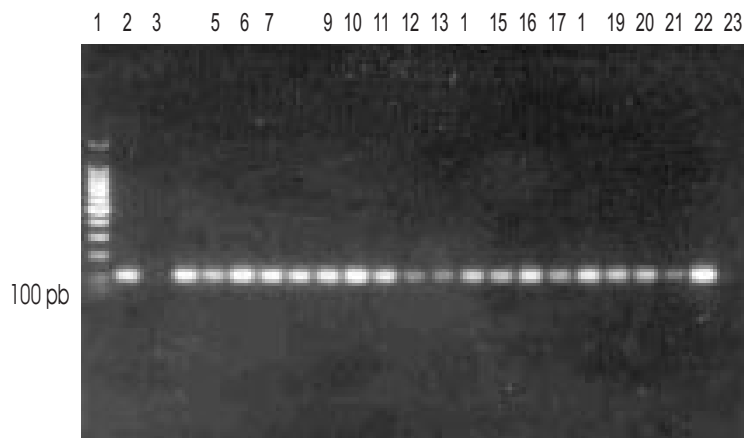

Figura 2. PCR con los iniciadores MF $\alpha$. Carril 1: marcador de peso molecular de $100 \mathrm{pb}$; 2: JEC 21 MAT $\alpha$; 3: JEC 20 MAT a; 4-22: aislamientos de Cryptococcus neoformans var. gattii códigos de estudio del 1-19; 23: control de la mezcla. obstante las variaciones morfológicas observadas, solamente un aislamiento que presentaba colonias rugosas fue virulento en el modelo animal.

En cuanto la morfología microscópica, $C$. neoformans se caracteriza por presentar una cápsula polisacárida, considerada un importante factor de virulencia (23). En este trabajo, se observó que los aislamientos de las dos variedades del hongo mostraban en cultivo una cápsula pequeña y de tamaño similar, lo cual había sido observado en estudios previos $(2,23)$. No obstante, in vivo los aislamientos de la variedad grubii que causaron la muerte de los animales produjeron cápsulas de gran tamaño. Esto ratifica que el tamaño de la cápsula es un factor importante que contribuye a la virulencia del hongo (2).

Enzimas extracelulares. En C. neoformans no es clara la relación entre la producción de enzimas extracelulares y la virulencia $(3,24,25)$. En cuanto a las proteasas, algunos estudios han mostrado menor producción in vitro en aislamientos de la variedad gattii, comparada con la de aislamientos de la variedad grubii (12). Los datos obtenidos ratifican la menor actividad en los aislamientos de la variedad gattii, lo cual a su vez podría relacionarse con los datos de virulencia en el modelo animal debido a que ningún aislamiento de esta variedad causó la muerte de los ratones. Otras enzimas como las fosfolipasas, se han asociado mediante estudios de disrupción genética con la virulencia de $C$. neoformans (26). Sin embargo, estudios realizados in vitro han mostrado actividad similar de fosfolipasas para las variedades del hongo $(18,3)$. En este trabajo observamos que los aislamientos de la variedad grubii mostraron mayor actividad enzimática que los aislamientos de la variedad gattii serotipo C, los cuales presentaron baja o ninguna actividad cuando se realizó la lectura en el día 6 . Este dato muestra, al igual que en las proteasas, diferencias que podrían correlacionarse con la virulencia en el modelo animal.

Es importante destacar que la lectura realizada el día 10 mostró un aumento en la actividad de la enzima en los aislamientos de la var. gattii, lo cual indica que, probablemente, el tiempo necesario para la expresión de la enzima in vitro es mayor, a diferencia de lo informado recientemente (27) 
sobre la ausencia de diferencias significativas cuando se evalúa la expresión de estas enzimas después de 6 días de incubación.

Una de las enzimas más estudiadas en este hongo es la fenoloxidasa, considerada como un importante factor de virulencia $(28,29)$. No obstante, existen pocos datos en la literatura acerca del rango de actividad de la enzima y su relación con la virulencia, por lo cual nuestros datos son interesantes porque muestran una mayor actividad en los aislamientos de la variedad grubii que en los aislamientos de la var. gattii. Adicionalmente, observamos que la actividad de esta enzima podría ser correlacionada con la virulencia en el modelo animal.

Por último, las actividades enzimáticas evaluadas mediante el sistema Api zim se consideran una alternativa para estudios de virulencia y tipificación (3). En este estudio encontramos perfiles diferentes a los informados en la literatura $(3,25,30)$, lo cual probablemente refleja diferencias geográficas.

Al estudiar los perfiles enzimáticos de los aislamientos de las dos variedades observamos que fueron similares, excepto por las diferencias observadas en el rango de actividad de 3 enzimas, fosfatasa alcalina, $\alpha$-glucosidasa, y $\beta$-glucosidasa. No obstante, no se observó relación entre la actividad enzimática de las 19 enzimas evaluadas por el sistema Api zim y la virulencia del microorganismo en el modelo animal.

Virulencia en el modelo en ratones. En el primer ensayo observamos que únicamente algunos de los aislamientos de la variedad grubii causaban la muerte de los animales, lo cual ratifica los datos informados en la literatura que señalan que la virulencia medida por la supervivencia de los ratones es una característica dependiente del aislamiento y es menor en los aislamientos de la variedad gattii $(2,19)$.

El efecto del inóculo en la virulencia se evaluó en un segundo ensayo y observamos que el aislamiento de la variedad grubii, independientemente del inóculo, causaba alteraciones en los animales en los primeros 20 días post-inoculación. El análisis macroscópico de los órganos reveló la presencia de hidrocefalia, un signo de infección grave. Estas observaciones mostraron, en el caso de este aislamiento en particular, que la virulencia fue expresada incluso en la concentración más baja del inóculo, probablemente por otras características adicionales, además de la alta actividad enzimática observada en los aislamientos de esta variedad. En contraste, los animales inoculados con las diferentes dosis del aislamiento de la var. gattii sobrevivieron hasta el final del periodo de observación.

Cuando se evaluó el recuento de UFC en órganos, encontramos que en los animales inoculados con las dos variedades se logró recuperar el hongo en el cerebro, lo cual recuerda el tropismo del hongo por el sistema nervioso central (6). Adicionalmente, para las dos variedades del hongo se observó la diseminación a otros órganos como pulmón y bazo.

En general, observamos la presencia de diferencias significativas entre aislamientos de las variedades grubii y gattii para los rangos de actividad de proteasas, fosfolipasas y fenoloxidasa y una mayor virulencia de los aislamientos de la variedad grubii en los ratones, lo cual nos sugiere que la expresión de estas enzimas es importante en la virulencia. No obstante, es necesario determinar y cuantificar su actividad in vivo para corroborar los datos in vitro obtenidos en este estudio. Además, es importante destacar el tamaño capsular de las blastoconidias, observadas en los órganos de los ratones inoculados con los aislamientos letales de la variedad grubii, pues ésto sugiere que la producción de una cápsula de gran tamaño in vivo es importante en el curso de la infección.

\section{Características asociadas con el ciclo de vida del hongo: tamaño capsular en suelo, fructificación haploide y pareja sexual}

In vitro se ha demostrado que $C$. neoformans se reproduce por formación de blastoconidias 0 basidiosporas; no obstante, se desconoce la frecuencia de estos propágulos en la naturaleza y, por tanto, cuál es la partícula infecciosa; sin embargo, modelos in vitro han mostrado que tanto las basidiosporas, por su tamaño, como las blastoconidias poco capsuladas menores de $3 \mu \mathrm{m}$, son propágulos infecciosos altamente efectivos 
(31-33). Con el fin de determinar si en la naturaleza se podrían producir blastoconidias poco capsuladas, se evaluó el tamaño de blastoconidias de las dos variedades del hongo cultivadas en suelo y observamos que, aunque el tamaño celular y capsular disminuyó significativamente comparada con el tamaño en caldo de Sabouraud, las blastoconidias no alcanzaron el tamaño que se considera adecuado para una partícula infecciosa altamente efectiva. Una de las causas que posiblemente influyó fue la humedad del suelo, ya que no fue posible controlarla con precisión. Por esta razón, se considera necesario realizar estudios que comparen condiciones controladas de humedad y desecación para definir su efecto en la generación de partículas infecciosas. En cuanto a la presencia de basidiosporas, es importante destacar que su producción por recombinación sexual es poco probable, debido a que los aislamientos fueron pareja sexual $\alpha$, lo que corrobora lo informado en la literatura sobre la alta frecuencia de esta pareja sexual $(16,34)$. Por esta razón, se considera de gran importancia la hipótesis que postula el fenómeno de fructificación haploide como un mecanismo de reproducción asexual alterno para producción de basidiosporas (4). Mediante este fenómeno, blastoconidias de pareja sexual $\alpha$ pueden formar tubos germinales, hifas y presentar basidios en los cuales se desarrollan basidiosporas semejantes a las producidas en la reproducción sexual; sin embargo, este tipo de reproducción se ha demostrado solamente in vitro, por lo cual se desconoce la frecuencia de este fenómeno en la naturaleza $(4,13,35)$. En este estudio observamos que algunos aislamientos de las dos variedades desarrollaron tubos germinales, lo cual indica una etapa inicial de formación de hifas y sugiere la frecuencia del fenómeno. No obstante, la escasa producción de basidiosporas puede indicar que las condiciones in vitro no fueron adecuadas para que se llevara a cabo todo el proceso.

En conclusión, observamos la frecuencia de blastoconidias de pareja sexual $\alpha$ que disminuyeron de tamaño en suelo y el desarrollo de estructuras asociadas con fructificación haploide, lo que sugiere que estos dos mecanismos pueden ser importantes en la generación de propágulos infecciosos en la naturaleza.

\section{Patrones de sensibilidad a toxinas}

Boekhout informó patrones de sensibilidad a toxinas producidas por diferentes especies de levaduras específicos para las variedades de $C$. neoformans (14). El autor considera que este fenómeno es de gran utilidad como herramienta epidemiológica. Por esta razón, determinamos los patrones de las variedades de $C$. neoformans de acuerdo con el esquema de Boekhout. Encontramos que en la variedad grubii predominó el patrón I, lo cual indica una homogeneidad en los aislamientos, lo cual está ratificado por un estudio paralelo realizado en el Grupo de Microbiología del INS, en el que, por las técnicas de PCR-huella digital y RFLP, se observó que estos aislamientos tenían un perfil molecular VN I con porcentajes de similitud entre $85 \%$ y $99 \%$ (comunicación personal, A. Castañeda, W. Meyer). En contraste, en los aislamientos de la variedad gattii encontramos 7 patrones diferentes, 3 de los cuales no habían sido informados previamente; esta variabilidad en los patrones indica que, probablemente, existen varias subpoblaciones del hongo, hallazgo que también fue corroborado en el estudio paralelo (comunicación personal, A. Castañeda, W. Meyer), en el cual se observó que la mayoría de estos aislamientos eran menos similares, con porcentajes que oscilaron entre $60 \%$ y $97 \%$, aunque la mayoría se agruparon en el patrón molecular VG III, lo que indica que esta técnica fenotípica puede resultar un buen complemento para el estudio de patrones moleculares en $C$. neoformans. Es importante resaltar que un aislamiento de la variedad gattii que presentó un patrón que según la literatura corresponde a un patrón específico para la variedad grubii, fue el único con un patrón molecular VG IV y un porcentaje de similitud de $36 \%$ comparado con los demás aislamientos de la var. gattii, lo cual puede indicar que algunos de los patrones de sensibilidad a toxinas previamente informados no son específicos de variedad. Por último, los resultados de este estudio permiten destacar la utilidad de estos patrones como una importante herramienta epidemiológica. 
En general, podemos concluir que la virulencia y la expresión de factores asociados con virulencia fue mayor para los aislamientos de la variedad grubii, lo que, probablemente, indica que las características fenotípicas estudiadas son importantes en el desarrollo y curso de la criptococosis en los ratones, por lo cual se requieren estudios in vivo para corroborar estos resultados y determinar si los aislamientos recuperados de muestras clínicas presentan un fenotipo similar. Adicionalmente, observamos que in vitro es probable obtener basidiosporas asexuales y blastoconidias pequeñas y poco capsuladas, lo cual puede ser de gran importancia en el ciclo de vida del hongo; sin embargo, se requieren estudios en el hábitat natural del hongo para determinar la importancia de estos eventos.

\section{Referencias}

1. Franzot SP, Salkin IF, Casadevall A. Cryptococcus neoformans var grubii: separate varietial status for Cryptococcus neoformans serotype A isolates. J Clin Microbiol 1999;37:838-40

2. Casadevall A, Perfect J. Cryptococcus neoformans. Washington, D.C.: American Society for Microbiology Press; 1998.

3. Vidotto V, Yumi-Koga-Ito C, Sinicco A, Perri G, Aoki S, Nakamura K. Extracelullar activity in Cryptococcus neoformans strains isolated from AIDS patients and from environmental sources. Rev Iberoam Micol 2000;17: 149.

4. Cabral LF. Wood, animals and human beings as reservoirs for human Cryptococcus neoformans infection. Rev Iberoam Micol 1999;16:77-81.

5. Evans EG, Richardson MD. Medical Mycology. Oxford, England: IR Press; 1989. p.187-96.

6. Kwon Chung KJ, Bennett JE. Medycal Mycology. Pennsylvania, U.S.A: Lea \& Febiger Press; 1992. p.397446.

7. Franzot SP, Mukherjee J, Cherniak R, Chen LC, Hamdan JS, Casadevall A. Microevolution of a standard strain of Cryptococcus neoformans resulting in differences in virulence and other phenotypes. Infect Immun 1998;66:89-97.

8. Chen LC. Casadevall A. Variants of a Cryptococcus neoformans elicit different inflammatory responses in mice. Clin Diagn Lab Immunol 1999;6:266-8.

9. Leone R, Cabeli P, Sinicco A, Ito Kuwa S, Vidotto V. Relationship between protease production and capsule size in Cryptococcus neoformans. J Mycol Med 1999;9: 42-4.
10. Price MF, Wilkinson ID, Gentry LO. Plate method for detection of phospholipase activity in Candida albicans. Sabouradia 1982;20:7-14.

11. Brueske $\mathbf{C H}$. Proteolytic activity of a clinical isolate of Cryptococcus neoformans. J Clin Microbiol 1986;23: 631-3.

12. Ruma P, Brownlee A, Sorrell T. A rapid method for detection of extracellular proteinase activity in Cryptococcus neoformans and a survey of 63 isolates. J Med Micobiol 2000;49:733-7.

13. Wickes BL, Mayorga ME, Edman U, Edman C. Dimorphism and haploid fruiting in Cryptococcus neoformans association with the mating type. Proc Natl Acad Sci 1996;93:7327-31.

14. Boekhout T, Scorzetti G. Diferential killer toxin sensitivity patterns of varieties of Cryptococcus neoformans. J Med Vet Mycol 1997;35:147-9.

15. Meyer W, Marszewska K, Amirmostofian M, Igreja RP, Hardtke C, Metheling K. Molecular typing of global isolates of Cryptococcus neoformans var. neoformans by polymerase chain reaction fingerprinting and randomly amplified polymorphic DNA: a pilot study to standardize techniques on which to base a detailed epidemiological survey. Electrophoresis 1999;20:17909 .

16. Halliday CL, Bui T, Krockenberger M, Malik R, Ellis DH, Carter DA. Presence of $\alpha$ and a mating types in environmental and clinical collections of Cryptococcus neoformans var gattii strains from Australia. J Clin Microbiol 1999;37:2920-6.

17. Hamilton J. Virulence factors of Cryptococcus neoformans. Current Top Med Mycol 1996;7:19-42.

18. Plentheweechai $\mathrm{K}$, Ito-Kowa $\mathbf{S}$, Nakamura $\mathrm{K}$, Oiki S, Vidotto V, Koga-Ito CY, et al. Phospholipase production in Cryptococcus neoformans isolates from AIDS patients in Thailand and Italy. $J$ Mycol Med 1999;9:45-8.

19. Castañeda E. En búsqueda del hábitat de Cryptococcus neoformans var. gattii en Colombia. Rev Acad Colomb Cienc 2001;25:105-15.

20. Odom A, Muri S, Lim E, Toffaletti DL, Perfect J. Calcineurin is required for virulence of Cryptococcus neoformans. EMBO J 1999;16:2576-89.

21. Fries B, Goldmand DL, Cherniak R, Rujin JU, Casadevall A. Phenotypic switching in Cryptococcus neoformans results in changes in cellular morphology and glucuronoxylomannan structure. Infect Immnun 1999;67:6076-83.

22. Fries B, Taborda CP, Serfass E, Casadevall A. Phenotypic switching of Cryptococcus neoformans occurs in vivo and influences the outcome of infection. J Clin Invest 2001;108:1639-48.

23. Kozel TR, Mastronianni RP. Inhibition of phagocytosis by cryptococcal polysaccharide: dissociation of the 
attachment and ingestion phases of phagocytosis. Infect Imnun 1976;14:62-7.

24. Buchanan KL, Murphy JW. What makes Cryptococcus neoformans a pathogen? Emerg Infect Dis 1998;4:115.

25. Chen SC, Wright LC, Golding JC, Sorrell TC Purification and characterization of secretory phospholipase B, lysophospholipase and lysophospholipase/transacylase from a virulent strain of the pathogenic fungus Cryptococcus neoformans. Biochem J 2000;347:431-9.

26. Chen SC, Pirofski LA, Casadevall A. Extracellar proteins of Cryptococcus neoformans and host antibody responses. Infect Immun 1997;65:2599-605.

27. Santamarina MP, Roselló J, Llacer R, Sanchis V. Estudio comparativo de dos medios de cultivo para la detección de la actividad fosfolipasa en cepas de Candida albicans y Cryptococcus neoformans. Rev Iberoam Micol 2002;19:95-8.

28. Zhun Y, Guibbons J, Garcia J, Casadevall A, Williamson P. Lacasse of Cryptococcus neoformans is a cell wall associated virulence factor. Infect Immun 2001;69:5589-96.

29. Salas S, Bennett J, Kwon-Chung K, Perfect J, Williamson P. Effect of the laccase gene, CNLAC1, on virulence of Cryptococcus neoformans. J Exp Med 1996;184:377-86.

30. Garcia P, Marin P, Hernandez JM, Garcia L, Aufi S, Mira J. Extracellular enzymatic activity in 11 Cryptococcus species. Mycopathologia 2001;150:1-4.

31. Sukroongreung S, Kitniyom K, Nilakkul C, Tantimavanich S. Pathogenicity of Filobasidiella neoformans var. neoformans. Med Mycol 1998;36:41924.

32. Neilson JB, Fromtiling RA, Bulmer GC. Cryptococcus neoformans: size range of infectious particles from aerosolized soil. Infect Immun 1997;17: 634-8.

33. Farhi F, Bulmer GS, Tacker JR. Cryptococcus neoformans the not so-encapsulated yeast. Infect Immun 1970:1:526-31.

34. Kwon Chung KJ, Bennet E. Distribution of $\alpha$ and a mating types of Cryptococcus neoformans among natural and clinical isolates. Am J Epidemiol 1978;108: 337-40.

35. Alspaugh JA, Davidson RC, Heitman J. Morphogenesis of Cryptococcus neoformans. Ernst. JF Schimidt A, editors. Contribu Microbial. Basel, Karger: 2000. p.217-38. 